\#97481

\title{
EXPERIMENTAL DATA FOR TWO DIFFERENT ALTERNATOR CONFIGURATIONS IN A SOLAR BRAYTON POWER SYSTEM
}

\author{
Lee S. Mason, Richard K. Shaltens, and William D. Espinosa \\ NASA Lewis Research Center \\ 21000 Brookpark Rd \\ Cleveland, Ohio 44135 \\ (216) 977-7106, (216) 433-6138, (216) 433-6474 \\ Fax (216) 433-8311
}

\begin{abstract}
A solar dynamic (SD) space power system has been under test at the NASA Lewis Research Center since 1994. The SD Ground Test Demonstration (GTD) system includes a solar concentrator, heat receiver with thermal energy storage, Brayton power conversion unit, and radiator installed in a thermal-vacuum chamber with a solar simulator. The Brayton unit has been operated with two different turboalternatorcompressor (TAC) assemblies, one which included a Rice-Lundell alternator and another which incorporated a permanent magnet (PM) alternator. The Rice alternator was part of the mini-Brayton rotating unit, designed and built during the 1970's and refurbished for the GTD The PM TAC was a development unit from the Joint US/Russian SD Flight Project.

This paper highlights the operational differences (and similarities) between the Rice and PM TAC configurations including a comparative evaluation of startup characteristics and operating performance. The two alternator configurations were tested under similar thermal conditions, as an interchangeable component within the SD system. The electrical characteristics of the two units, however, dictated the use of significantly different power conditioning and control strategies. The electrical control architectures are described and compared. Test data are presented on TAC startup and system operating performance for both configurations.
\end{abstract}

\section{BACKGROUND}

In order to demonstrate the technology readiness of solar dynamic power systems, the Solar Dynamic Ground Test Demonstration (SD GTD) project was initiated in 1992. The goal of the project was to build and test a complete, integrated power system in a simulated space environment (Shaltens, 1995). The SD system, shown in figure 1, includes the following major subsystems: 1) a solar concentrator, 2) a heat receiver with thermal energy storage, 3) a Brayton power conversion unit including turbomachinery, recuperator, and cooler, 4) a waste heat radiator system, and 5) an electrical control system including a power conditioning and control unit (PCCU) and parasitic load radiator (PLR). The test was conducted in the Tank 6 thermal-vacuum facility at the NASA Lewis Research Center. The Tank 6 facility includes a vacuum system to simulate the space environment $\left(<1 \times 10^{-5}\right.$ torr), a solar simulator to supply Earth orbital solar flux (1 Sun, or $\left.1.37 \mathrm{~kW} / \mathrm{m}^{2}\right)$, and a liquid-nitrogen $\left(\mathrm{LN}_{2}\right)$ coldwall to provide representative sink temperatures (about $200 \mathrm{~K}$ ). The solar simulator uses nine $30 \mathrm{~kW}$ Xenon arc lamps to provide insolation at the target plane (up to 1.2 Suns) within a subtense angle of less than 1 degree. A water-cooled shutter is opened and closed to simulate orbital sun/shade cycles.

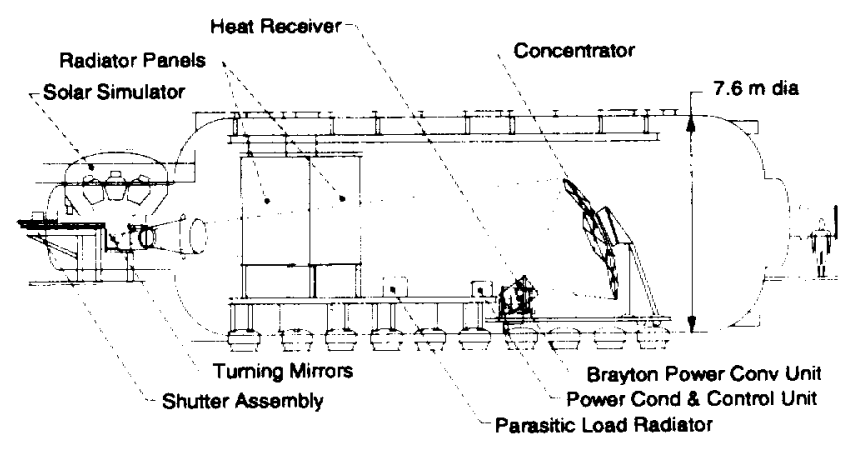

FIGURE 1. SD GTD TEST LAYOUT

The SD GTD system was designed to produce an average orbital power of about $2 \mathrm{kWe}$. To minimize cost, the system used existing hardware and designs provided from previous development efforts including the Brayton Isotope Power System (BIPS) 
Program and the Space Station Freedom (SSF) SD Power Module Program. Due to the varying origin and design heritage of the components, the system was not optimized for either performance or life. However, the SD GTD system was assembled in a modular fashion to allow replacement of components as newer technology becomes available. AlliedSignal, Aerospace Equipment Systems, served as the prime contractor for both the SD GTD and subsequent SD Flight Demonstration projects.

\section{SYSTEM DESCRIPTION}

The mini-Brayton Rotating Unit (mini-BRU) and recuperator developed and tested in the early 1970's BIPS Program was used to convert the thermal energy from the heat receiver into electrical power (Amundsen and Harper, 1993). The original BIPS hardware units were removed from storage and refurbished for the SD GTD test program. The turboalternator-compressor (TAC), shown in figure 2, consists of a single stage radial flow compressor and turbine with a Rice-Lundell alternator. The rotor was supported by two journal foil bearings and one thrust foil bearing. The bearing cavity was gas cooled using bleed flow from the compressor. The recuperator was a counterflow plate-fin heat exchanger designed to provide $97.5 \%$ heat transfer effectiveness. An inert gas mixture (Helium-Xenon, 83.8 molecular weight) was the working fluid and the design rotor speed was $52000 \mathrm{rpm}$. Two counter flow gas coolers were used to transfer the cycle waste heat to a liquid coolant ( $\mathrm{n}$-heptane).

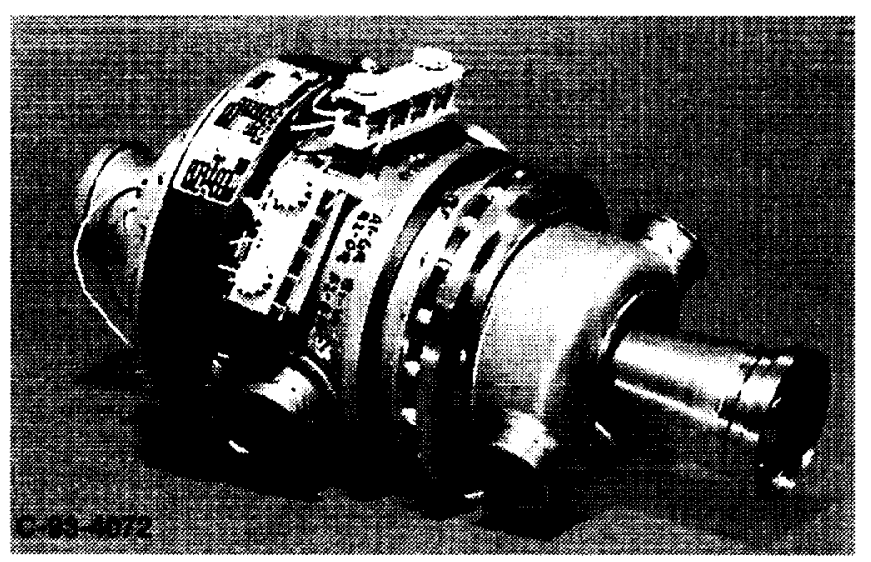

FIGURE 2. MINI-BRU TAC

The Rice TAC was replaced in September 1996 with a unit built for the Joint US/Russian Solar Dynamic Flight Demonstration Project. The flight project was planned to demonstrate a $2 \mathrm{kWe}$ SD system on the Mir Space Station beginning in 1997 (Wainhainen and Tyburski, 1995). While the project was canceled due to Shuttle manifest changes, a significant portion of the hardware was completed including a development TAC. The flight development TAC was very similar to the mini-BRU TAC with comparable turbomachinery and bearings. There were two primary differences between the mini-BRU TAC and the flight development TAC: the Rice-Lundell alternator was replaced by a permanent magnet (PM) alternator, and the bus voltage was changed from $120 \mathrm{Vdc}$ for the Rice machine (a requirement derived from SSF) to $28 \mathrm{Vdc}$ for the PM TAC as required for Mir.

The SD GTD system accumulated over 700 hours of operation (562 hours with the Rice alternator and 142 hours with the PM alternator) since its introduction in December 1994, and has provided considerable insight into the performance characteristics and operational features of an SD system.

\section{Rice-Lundell Alternator Configuration}

The 3 phase, 1733 hertz ac electrical output of the RiceLundell alternator was conditioned by the PCCU with a rectifier and filter circuit to provide a nominal $120 \mathrm{Vdc}$ to the user (Post, 1993). The PCCU electrical control layout is shown in figure 3. The PCCU was a digital controller with a 50 millisecond update rate which used proportional plus integral control algorithms to maintain both $\mathrm{dc}$ bus voltage and rotor speed. Voltage was regulated through external field excitation of the alternator windings. Speed was maintained through modulation of the PLR, used to dissipate excess power from the system that was not required by the load. While the Rice electrical controls were designed to be flight prototypic (vacuum compatible), the PCCU and PLR were operated outside the vacuum chamber for the majority of the test program to permit access for detailed electrical measurements.

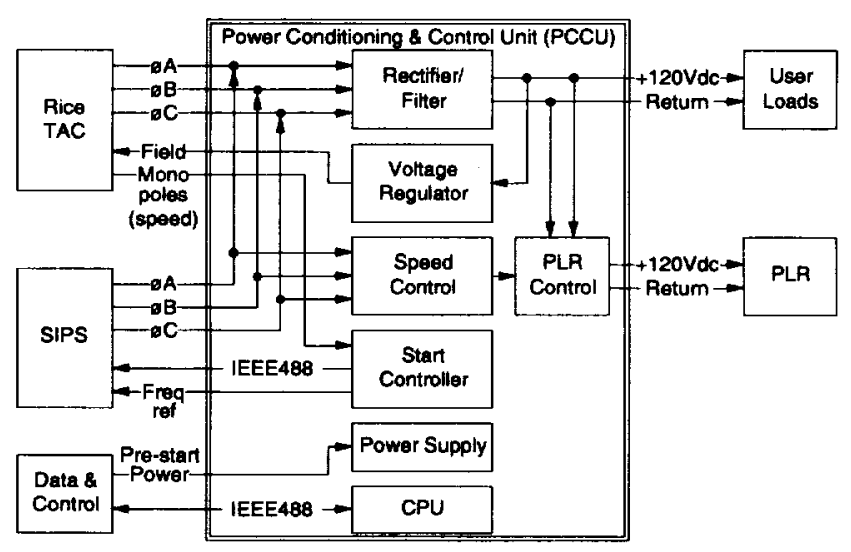

\section{FIGURE 3. RICE ALTERNATOR PCCU LAYOUT}

A commercial 3 phase, start inverter power supply (SIPS) was used to operate the alternator as a $400 \mathrm{hz}$ induction motor for startup. After speed and rotor position were acquired with monopole sensors (several seconds after initiating a start), the PCCU switched to synchronous mode and applied field excitation to the alternator windings. The switch to synchronous motoring was performed to reduce the startup current demand. The initial induction phase was required because the monopoles can not sense static position. Startup motoring was maintained until the TAC no longer required power from the SIPS at which time the unit was self-sustaining and could be commanded to the desired operating speed. 


\section{Permanent Magnet Alternator Configuration}

The PM alternator electrical control diagram is shown in figure 4. A version of the SD/Mir flight PCCU was not available for Tank 6 testing. AlliedSignal supplied a "breadboard" controller that provided fundamental startup circuitry and speed control. The breadboard controller, located outside the vacuum chamber, was not flight prototypic and served only to maintain engine speed by pulse-width load modulation of a PLR.

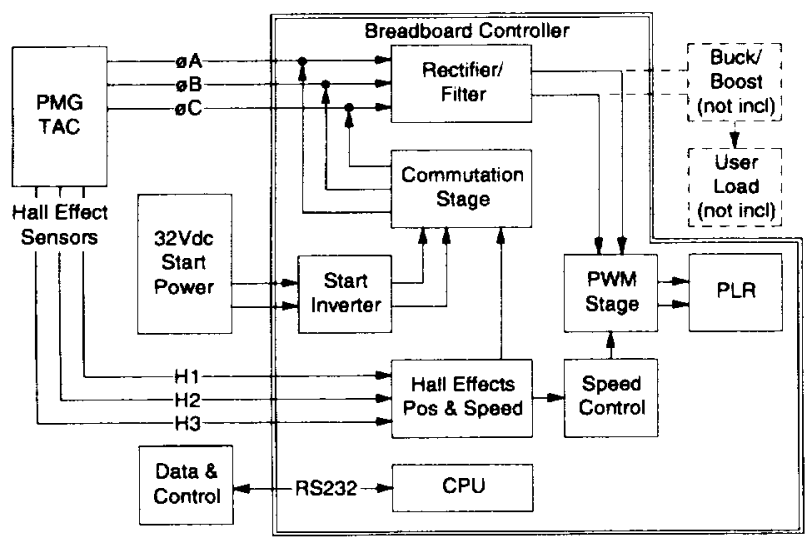

\section{FIGURE 4. BREADBOARD CONTROLLER LAYOUT}

The PM TAC was designed for a $28 \mathrm{Vdc}$ bus, consistent with the Mir Space Station. Unlike the Rice machine which produced a constant output voltage based on field excitation control, the PM alternator voltage varied with speed and load, according to the rotor magnet strength. Voltage regulation with the flight PCCU was to be accomplished through separate buck and boost converter stages attached to the output of the rectifier/filter. These converters were not included in the breadboard controller, which precluded evaluation of the dc output power and associated user load interactions. Figure 5 shows the current-voltage characteristics of the PM TAC at $56000 \mathrm{rpm}$.

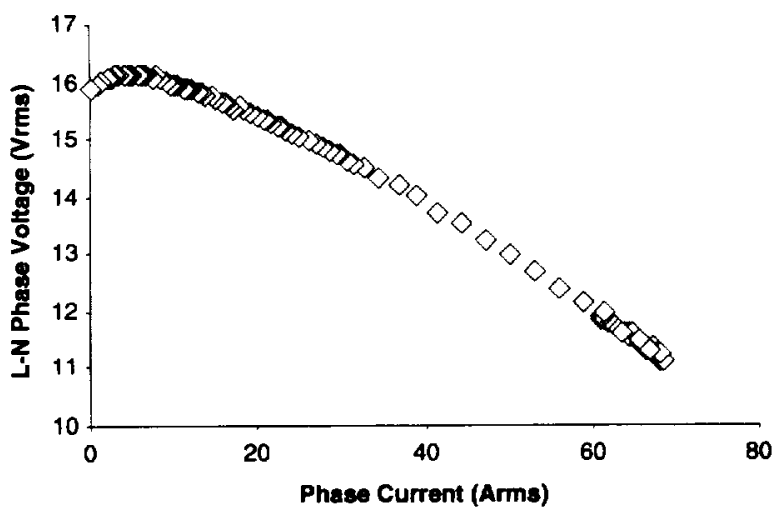

FIGURE 5. PM ALTERNATOR I-V CURVE AT 56000 RPM
Startup of the PM TAC was accomplished using a commercial dc power supply connected to the start inverter. During startup, the PM alternator had to be motored entirely in a synchronous mode because the excessive power associated with induction motoring could have potentially damaged the magnets. Instead of monopole sensors, the PM machine used Hall effect sensors which provided static position sensing and allowed the unit to be motored in a synchronous mode from zero speed.

There was one modification from the Rice system which was made for the PM TAC that effected the thermal characteristics of the Brayton unit. Five layers of high temperature multi-foil insulation (MFI) were added to the turbine plenum. Previously, the TAC heat losses were controlled using a cylindrical MFI shroud surrounding the TAC and local ducting. Surface mounted thermocouples installed near the plenum indicated a sizable temperature drop (about $40 \mathrm{~K}$ ) relative to thermocouples mounted at the receiver discharge. The apparent heat losses were presumed to have been mitigated with the additional MFI, which reduced the temperature drop by a factor of 4 .

\section{SYSTEM OPERATION}

A photograph showing the Brayton power conversion unit installed with the heat receiver is provided in figure 6 (the receiver is on the right side). The TAC was mounted vertically, in the center of the Brayton gas loop, with the turbine end at the top. The Brayton gas circuit was configured the same for both alternator configurations. The working fluid was heated in the receiver to about $1050 \mathrm{~K}$ and entered the turbine where it was expanded. The turbine provided the mechanical power to drive the alternator and compressor. The turbine exhaust flowed through the recuperator to pre-heat the counterflow gas before entering the receiver. After the recuperator, the gas flowed through the gas coolers where the waste heat was transferred to the liquid coolant. Following the coolers, the cold working fluid (about $250 \mathrm{~K}$ ) was pressurized by the compressor and flowed through the alternator housing to provide stator cooling. The gas was then pre-heated in the recuperator and returned to the heat receiver. The nominal gas flow rate, which varied with rotor speed and gas inventory, was about $0.15 \mathrm{~kg} / \mathrm{sec}$.

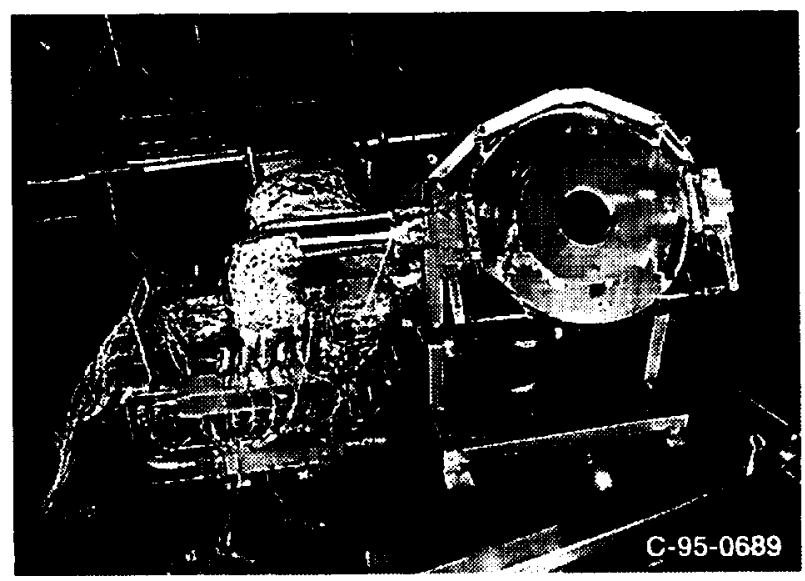

FIGURE 6. BRAYTON PCU AND HEAT RECEIVER 
The heat receiver included thermal energy storage (TES) consisting of $\mathrm{LiF}-\mathrm{CaF}_{2}$ eutectic phase change salt (melt temperature of $1040 \mathrm{~K}$ ) contained in canisters surrounding the receiver flow tubes. The TES absorbed heat during the sun period and supplied heat to the working fluid through the eclipse in order to maintain continuous power production.

\section{Test Plan Overview}

A typical GTD test run consisted of five steps, which included: 1) establishing the test environment, 2) illuminating the concentrator to heat the receiver, 3) starting the TAC, 4) operating the system to satisfy the intended test objectives, and 5) TAC shutdown and return to ambient. After tank vacuum was achieved and the $\mathrm{LN}_{2}$ coldwalls were activated, the receiver was heated in a cyclic mode representative of an orbital sun/shade cycle. When the proper thermal conditions were achieved, the TAC was motored to self-sustaining operation and commanded to a nominal run speed for power generation.

Following TAC startup, the system was operated over a range of conditions according to the test plan. The test variables included solar flux level, orbit period, rotor speed, gas inventory, radiator coolant flow rate, and radiator area (area variations were achieved by blanketing portions of the radiator panels with mylar insulation) Typically, the test variables were established and the system was operated until a thermal equilibrium was achieved. After the test points were collected, the TAC was shutdown and the system was allowed to return to ambient temperature before repressurizing the vacuum tank.

\section{TAC Startup}

Thermal Conditions for Startup. The thermal conditions imposed for starting the TAC were similar for both alternator configurations. The receiver was heated from ambient to about $1050 \mathrm{~K}$ (average TES canister temperature). The time required to heat the receiver sufficiently for TAC startup varied from 1.3 to 5.8 hours depending on the solar simulator flux output and orbit period. During the heatup, the working fluid in the receiver was heated by conduction to about $400 \mathrm{~K}$ before initiating motor startup of the TAC. The cycle temperature ratio (ratio of turbine inlet temperature to compressor inlet temperature) proved to be a dependable parameter to indicate TAC start readiness. Figure 7 presents the TAC motoring time sensitivity to temperature ratio. The data points represent all of the Rice and PM TAC starts following an ambient receiver heatup. Lower temperature ratios led to long motoring times. The data indicates that heating the receiver beyond a temperature ratio of about 1.6 yields minimal benefit in motor time savings. A trade-off exists between the time heating the receiver without power production versus the time and power requirement for starting the TAC. A shorter heating period brings the power system on-line quicker. By extending the heating duration, motoring times and startup energy requirements are reduced.

The startup procedure for the TAC included the use of bypass valves in the gas loop which served to separate the hot-side of the gas loop from the cold-side during motoring. These bypass valves were originally intended for TAC shutdown as a means to unload the compressor and cause an expedient deceleration of the rotor. The two valves, configured in series for redundancy, were located between the compressor exit duct and the cooler inlet duct. During subsystem testing of the mini-BRU TAC at AlliedSignal, it was discovered that motoring with the valves open resulted in a more rapid rise in cycle temperature ratio, and a corresponding reduction in motoring time (Alexander, 1997). The open-valve motoring provided an efficient method for preheating the turbine by limiting the flow of the heated gas to the receiver, turbine and recuperator, thus avoiding temperature loss in the cold-side components. When a suitable temperature ratio was achieved, the bypass valves were closed and the motoring was continued until the unit was selfsustaining.

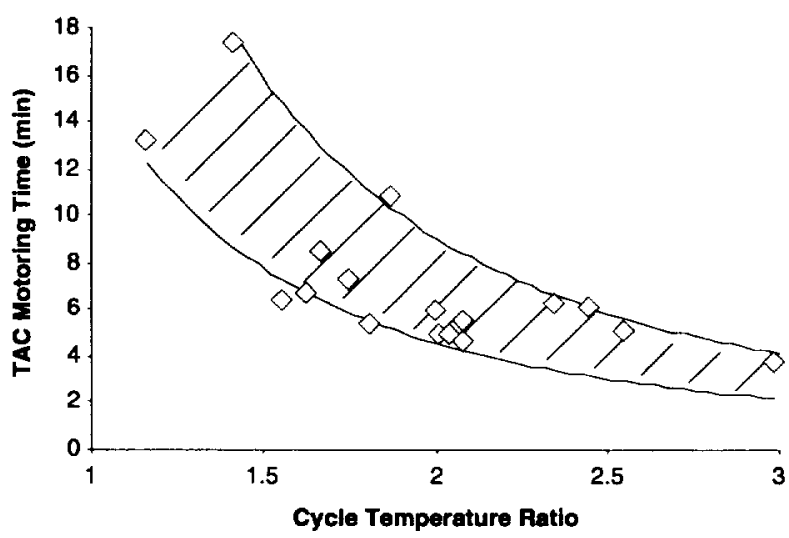

\section{FIGURE 7. TAC MOTOR TIME VARIATIONS}

Electrical Transients during Startup. The TAC electrical startup was heavily influenced by the electrical control system and startup power supply. However, comparisons between the two alternator configurations could be made by examining current and voltage at the alternator terminals. Table 1 presents a sampling of the PM TAC starts. Data are presented on turbine inlet temperature (TIT) and cycle temperature ratio (before starting to motor), total motoring time, average line-to-neutral (L-N) rms voltage (during motoring), total 3 phase rms charge current, and total ac energy demand. Turbine inlet temperatures greater than $500 \mathrm{~K}$ indicate hot restarts performed after TAC shutdowns with the receiver still near operating temperature. The energy demand was determined by integrating the ac power at the alternator terminals, measured with a commercial 3 phase power meter, over the motoring time. Among the nominal starts, cycle temperature ratio varied from a low of 1.17 (TAC\#17) to a high of 1.81 (TAC\#12). As expected, the low temperature ratio start resulted in the longest motoring time (13.5 minutes) and the highest energy requirement (131 W-hrs) while the high temperature ratio start yielded minimums for start time (5.33 minutes) and energy demand ( $41.2 \mathrm{~W}$-hrs).

Hot restarts of the TAC were performed with the turbine inlet temperature as high as $1018 \mathrm{~K}$. The hot restarts usually resulted in an acceleration to the run speed immediately after closing the bypass valves. The electrical energy demand of a typical hot restart (>700 K TIT) was negligible. The hot restart energy levels indicated in table 1 , are predominantly the result of unnecessary motoring with the bypass valves open. 
TABLE 1. PM TAC STARTUP SUMMARY

\begin{tabular}{|l|c|c|c|c|c|c|}
\hline TAC\# & $\begin{array}{c}\text { TIT, K } \\
\text { @ Start }\end{array}$ & $\begin{array}{c}\text { Tratio } \\
\text { Q Start }\end{array}$ & $\begin{array}{c}\text { Motor, } \\
\text { min }\end{array}$ & $\begin{array}{c}\text { L-N, } \\
\text { Vrms }\end{array}$ & $\begin{array}{c}\text { Charge, } \\
\text { A-hrs }\end{array}$ & $\begin{array}{c}\text { Energy, } \\
\text { W-hrs }\end{array}$ \\
\hline 17 & 325 & 1.17 & 13.5 & 11.2 & 13.1 & 131 \\
3 & 439 & 1.61 & 6.33 & 11.6 & 4.34 & 48.7 \\
8 & 447 & 1.63 & 7.00 & 10.8 & 4.65 & 45.3 \\
12 & 476 & 1.81 & 5.33 & 11.4 & 4.00 & 41.2 \\
10 & 482 & 1.75 & 7.33 & 11.4 & 4.93 & 50.6 \\
$5^{*}$ & 525 & 1.88 & 6.33 & 11.7 & 3.75 & 42.0 \\
$4^{*}$ & 770 & 2.84 & 2.00 & 11.5 & 2.08 & 22.8 \\
$15^{\star}$ & 860 & 3.56 & 1.83 & 11.9 & 1.31 & 14.2 \\
$6^{*}$ & 876 & 3.20 & 0.67 & 11.6 & 0.74 & 7.4 \\
$20^{*}$ & 1018 & 4.41 & 0.83 & 11.3 & 0.09 & 0.9 \\
\hline
\end{tabular}

* Indicates hot restart.

Rice versus PM Startup Transient. Figure 8 presents a comparison of a nominal Rice and PM TAC start (the PM start is TAC\#8 from table 1). RMS phase current and rotor speed are plotted against time in log scale. The two starts were performed under similar thermal conditions with temperature ratios of 1.56 and 1.63, respectively for the Rice and PM machines. Both starts required 7 minutes of motoring before self-sustaining operation was achieved, including 2 minutes with the bypass valves open. The charge current for the Rice start was based on an average L-N phase voltage of 35.4 Vrms while the PM start was performed with an average $\mathrm{L}-\mathrm{N}$ voltage of $10.8 \mathrm{Vrms}$.

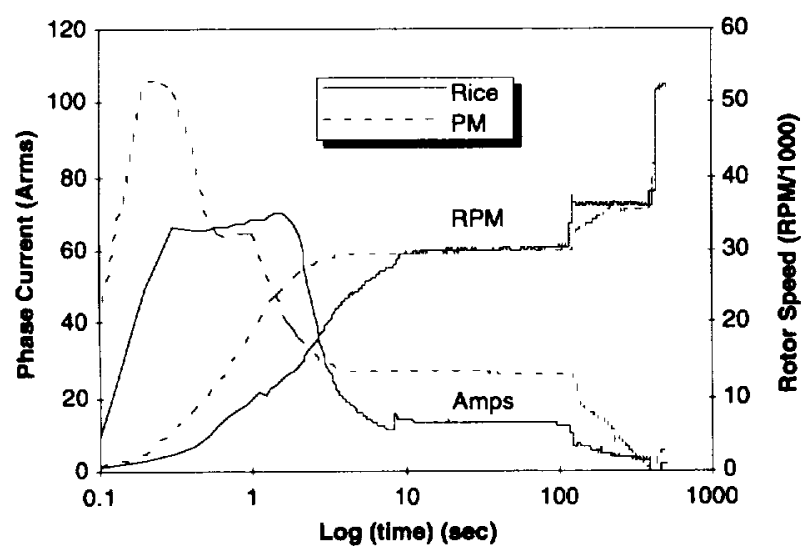

FIGURE 8. RICE vs PM TAC START

The initial induction motoring phase of the Rice machine was marked by a peak power demand of almost $5.9 \mathrm{kVA}$ (3 Phases $\mathrm{x} 68$ Amps $x 29$ Volts), while the PM peak power draw was about 1.6 kVA ( $3 \times 65 \times 8$ ), operating in synchronous mode only. During the $30000 \mathrm{rpm}$ turbine pre-heat phase, both machines maintain near constant current and voltage draw. After the bypass valves were closed, the PM unit exhibited a sharp decline in current and a gradual increase in rotor speed as the TAC accelerated to 36000 $\mathrm{rpm}$. The Rice machine acceleration to $36000 \mathrm{rpm}$ was immediate, and after an initial drop, the current decline was more gradual than the PM machine. These transients were presumed to be the result of controller differences and not necessarily indicative of the alternator's operating characteristics. The total charge current for the Rice start was $2.41 \mathrm{Amp}-\mathrm{hrs}$ (85.3 VA-hrs) versus $4.65 \mathrm{Amp}-$ hrs (50.2 VA-hrs) for the PM alternator.

\section{Operating Performance}

Steady-state Operation. Steady-state operating points were collected with the solar simulator shutter open for continuous illumination of the concentrator and heating of the receiver. They provided an excellent means of evaluating analytical tools since transients could be ignored. The criteria for steady-state test points was less than $2.8^{\circ} \mathrm{C} / \mathrm{hr}$ change in the receiver gas inlet and exit temperatures. Several of the steadystate operating points collected during the PM TAC testing were similar to points acquired with the Rice TAC. Two pairs of similar test points are compared in table 2 The four points were collected with the TAC at $52000 \mathrm{rpm}$. All of the parameters indicated in the table are measured except gas heat input and cycle efficiency. Gas heat input is the product of the gas mass flow rate (measured), specific heat (standard fluid property) and gas temperature increase through the receiver (measured). Cycle efficiency is the ratio of ac power output to gas heat input.

\section{TABLE 2. STEADY-STATE POINT COMPARISON}

\begin{tabular}{|l|c|c|c|c|}
\hline Test Pt. & Rice41 & PM10 & Rice40 & PM12 \\
\hline Gas Heat Input, kWt & 5.68 & 5.76 & 6.43 & 6.48 \\
AC Power, kWe & 1.35 & 1.42 & 1.75 & 1.75 \\
Turb Inlet Temp, K & 921 & 921 & 999 & 994 \\
Turb Inlet Press, kP\& & 569 & 591 & 594 & 612 \\
Comp Inlet Temp, K & 238 & 241 & 240 & 240 \\
Cycle Efficiency & $23.8 \%$ & $24.7 \%$ & $27.2 \%$ & $27.1 \%$ \\
\hline
\end{tabular}

The Rice and PM data points show very good agreement. The two higher power test points were nearly identical. A slight power and efficiency advantage was evident for "PM10" relative to "Rice41". The advantage for the PM data point was attributed to several possible factors: experimental error, higher operating pressure, reduced turbine plenum heat losses, and/or higher alternator electromagnetic efficiency which has been claimed for the PM alternator.

Cyclic Orbltal Operation. A solar dynamic power system is best utilized in an orbital application where full advantage of the receiver thermal energy storage (TES) can be realized. An SD system with TES provides a factor of 2 to 3 improvement in overall system efficiency over conventional photovoltaic/battery systems. Numerous orbital test points were collected during the GTD test program and were discussed in previous reports (e.g., Shaltens and Mason, 1996). Test points were declared when the receiver reached a cyclical thermal equilibrium, the criteria being a difference in the receiver gas temperatures of less than $2.8{ }^{\circ} \mathrm{C}$ on successive orbital sunrises (shutter opening) and sunsets (shutter closing).

A typical orbital operating condition produced a variable power output over the orbit period due to the fluctuation in receiver gas 
exit temperature as the receiver was heated during the sun period and cooled during the eclipse. Figure 9 shows the variation in ac power output for similar Rice and PM TAC orbital test points. The curves were collected with the solar simulator supplying the equivalent of 1.2 Suns insolation for 66 minutes of a 93 minute orbit period and the TAC speed at $52000 \mathrm{rpm}$. The power curves were very similar with the Rice profile showing slightly greater variation. This discrepancy is presumed to be the result of minor variations associated with the thermal system including those caused by the newly installed turbine plenum MLI, and not caused by the electrical differences of the alternators. Table 3 presents a performance comparison of the two orbital test points including energy flow, and sunset (SS) operating parameters. There was a modest efficiency advantage apparent for the PM point, but the difference was well within the experimental error. The ratio of alternator output energy to concentrator incident light energy provides a measure of the orbital efficiency.

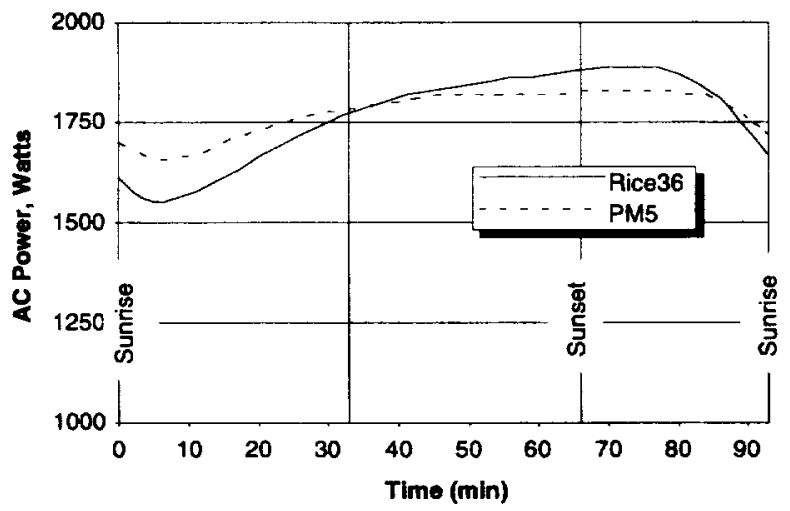

FIGURE 9. ORBITAL POWER PROFILE COMPARISON

TABLE 3. COMPARISON OF SIMILAR ORBITAL POINTS

\begin{tabular}{|l|c|c|}
\hline Test Pt. & Rice36 & PM5 \\
\hline Conc Solar Input, kWt-hr & 16.26 & 16.12 \\
Gas Heat Input, kWt-hr & 10.11 & 9.94 \\
AC Power, kWe-hr & 2.74 & 2.75 \\
SS Turb Inlet Temp, K & 1036 & 1041 \\
SS Turb Inlet Press, kPa & 609 & 614 \\
SS Comp Inlet Temp, K & 243 & 243 \\
Cycle Efficiency & $27.1 \%$ & $27.7 \%$ \\
Obit Efficiency & $16.9 \%$ & $17.1 \%$ \\
\hline
\end{tabular}

\section{SUMMARY AND CONCLUSION}

The Brayton power conversion unit in the SD GTD system was operated with two different TAC assemblies, one which used a Rice-Lundell altemator and another which used a PM alternator. The Rice alternator was part of the mini-BRU TAC, designed and built during the 1970's BIPS Program and refurbished for the GTD testing. The PM TAC was a development unit provided from the Joint US/Russian SD Flight Project. The two alternators required significantly different electrical control systems, based on their design and operating characteristics.

The testing of the two alternators did not indicate a particular preference. The alternator selection for future SD space systems will likely be based on cost and reliability issues. However, the tests provided insight into the startup and operating subtleties of the two configurations. The startup transient for the Rice machine was considerably different than the PM TAC with lower charge current but higher voltage. The integrated energy requirement for the Rice unit was a factor of 1.7 higher than the PM unit under similar starting conditions, partly because the Rice alternator was inductively motored for the first several seconds before transitioning to synchronous motoring. Nominal TAC starts with the PM alternator required about 5 to 7 minutes of motoring time and between 40 and 50 watt-hrs (at the alternator terminals) from an external power supply. During operation, the Rice machine offered the advantage of constant output voltage through field excitation control, while the PM machine's output voltage varied with speed and load. Additional electronics, not included in the test controller, would be required for the PM system to provide regulated voltage. Despite the electrical differences of the alternators, the operating performance of the two units was nearly identical. Cycle efficiencies of greater than $27 \%$ were achieved with both configurations. In an orbiting mode, the SD system exhibited a sun-to-user energy efficiency of $17 \%$.

Follow-on testing of the PM TAC, modified for higher output voltage, and coupled to an electrical control system more comparable to the Rice PCCU, is planned for 1998. The additional testing will expose performance characteristics of the PM configuration including ac-to-dc efficiencies and spacecraft load interactions, already evaluated with the Rice unit.

\section{References}

Alexander, D., " 2 kWe Solar Dynamic Ground Test Demonstration Project”, NASA CR 198423, 1997.

Amundsen, P. C. and Harper, W. B., "BIPS

Turboalternator-Compressor Characteristics and Application to the NASA Solar Dynamic Ground Demonstration Program", Proceedings of the 28th Intersociety Energy Conversion Engineering Conference, 1993, pp. 239-244.

Post, P., "Solar Dynamic Ground Test Demonstrator (SDGTD) Power Conditioning and Control Unit (PCCU) Critical Design Review (CDR) Package Report", AlliedSignal Contractor Report, 41-12105, May 12, 1993.

Shaltens, R. K., "Overview of the Solar Dynamic Ground Test Demonstration Program at the NASA Lewis Research Center", NASA TM-106876, 1995.

Shaltens, R. K. and Mason, L. S., "Early Results from Solar Dynamic Space Power System Testing", Journal of Propulsion and Power, AIAA Publication, Volume 12, Number 5 , September-October, 1996, pp. 852-858.

Wanhainen, J. S., and Tyburski, T. E., "Joint US/Russian Solar Dynamic Flight Demonstration Project Plan", Proceedings of the 30th Intersociety Energy Conversion Engineering Conference, 1995, pp. 417-420. 


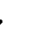




\begin{tabular}{|c|c|c|c|c|}
\hline \multicolumn{3}{|c|}{ REPORT DOCUMENTATION PAGE } & \multicolumn{2}{|r|}{$\begin{array}{l}\text { Form Approved } \\
\text { OMB No. 0704-0188 }\end{array}$} \\
\hline \multicolumn{5}{|c|}{ 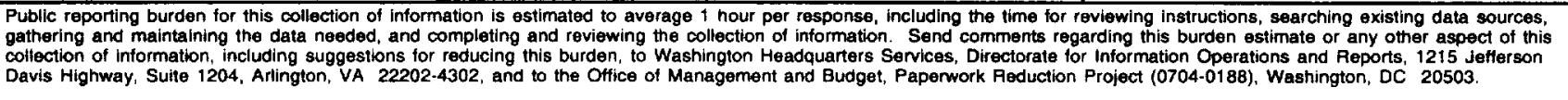 } \\
\hline 1. AGENCY USE ONLY (Leave blank) & \multicolumn{2}{|l|}{$\begin{array}{r}\text { 2. REPORT DATE } \\
\text { July } 1997\end{array}$} & \multicolumn{2}{|c|}{$\begin{array}{l}\text { AND DATES COVERED } \\
\text { Technical Memorandum }\end{array}$} \\
\hline \multicolumn{3}{|c|}{$\begin{array}{l}\text { 4. TITLE AND SUBTITLE } \\
\text { Experimental Data for Two Different Alternator Configurations in a } \\
\text { Solar Brayton Power System }\end{array}$} & \multicolumn{2}{|c|}{ 5. FUNDING NUMBERS } \\
\hline \multicolumn{3}{|l|}{ 6. AUTHOR(S) } & \multicolumn{2}{|c|}{ WU $-547-10-41$} \\
\hline $\begin{array}{l}\text { 7. PERFORMING ORGANIZATION } \\
\text { National Aeronautics and } \\
\text { Lewis Research Center } \\
\text { Cleveland, Ohio } 44135 \text { - }\end{array}$ & $\begin{array}{l}\text { NAME(S) AND ADDRESS(ES) } \\
\text { Space Administration } \\
191\end{array}$ & & \multicolumn{2}{|c|}{ E-10811 } \\
\hline \multicolumn{3}{|c|}{ 9. SPONSORINGMONITORING AGENCY NAME(S) AND ADDRESS(ES) } & 10. $s$ & $\begin{array}{l}\text { NSORINGMONITORING } \\
\text { ECY REPORT NUMBER } \\
\text { SA TM-107509 }\end{array}$ \\
\hline \multicolumn{5}{|c|}{$\begin{array}{l}\text { 11. SUPPLEMENTAAY NOTES } \\
\text { Prepared for the 32nd Intersociety Energy Conversion Engineering Conference cosponsored by AIChE, ANS, SAE, } \\
\text { AIAA, ASME, and IEEE, Honolulu, Hawaii, July 27-August 1, 1997. Responsible person, Lee S. Mason, organization } \\
\text { code 5490, (216) 977-7106. }\end{array}$} \\
\hline \multicolumn{4}{|c|}{\begin{tabular}{l|l} 
129. DISTRIBUTIONAVAILABILITY STATEMENT & 12 \\
Unclassified - Unlimited & \\
Subject Category 20 & \\
& \\
This publication is available from the NASA Center for AeroSpace Information, (301) 621-0390. & \\
\end{tabular}} & 12b. DISTRIBUTION CODE \\
\hline \multicolumn{5}{|c|}{$\begin{array}{l}\text { A solar dynamic (SD) space power system has been under test at the NASA Lewis Research Center since 1994. The SD } \\
\text { Ground Test Demonstration (GTD) system includes a solar concentrator, heat receiver with thermal energy storage, } \\
\text { Brayton power conversion unit, and radiator installed in a thermal-vacuum chamber with a solar simulator. The Brayton } \\
\text { unit has been operated with two different turboalternator compressor (TAC) assemblies, one which included a Rice } \\
\text { Lundell alternator and another which incorporated a permanent magnet (PM) alternator. The Rice alternator was part of } \\
\text { the mini-Brayton rotating unit, designed and built during the 1970's and refurbished for the GTD. The PM TAC was a } \\
\text { development unit from the Joint US/Russian SD Flight Project. This paper highlights the operational differences (and } \\
\text { similarities) between the Rice and PM TAC configurations including a comparative evaluation of startup characteristics } \\
\text { and operating performance. The two alternator configurations were tested under similar thermal conditions, as an } \\
\text { interchangeable component within the SD system. The electrical characteristics of the two units, however, dictated the } \\
\text { use of significantly different power conditioning and control strategies. The electrical control architectures are described } \\
\text { and compared. Test data are presented on TAC startup and system operating performance for both configurations. }\end{array}$} \\
\hline \multicolumn{3}{|l|}{ 14. SUBJECT TERMS } & & 15. NUMBER OF PAGES \\
\hline \multirow{2}{*}{\multicolumn{3}{|c|}{ Space power; Solar dynamic; Brayton cycle; System testing }} & & 8 \\
\hline & & & & $\begin{array}{r}\text { 16. PAICE CODE } \\
\mathrm{A} 02\end{array}$ \\
\hline $\begin{array}{l}\text { 17. SECURITY CLASSIFICATION } \\
\text { OF REPOAT } \\
\text { Unclassified }\end{array}$ & $\begin{array}{l}\text { 18. SECURITY CLASSIFICATION } \\
\text { OF THIS PAGE } \\
\text { Unclassified }\end{array}$ & $\begin{array}{l}\text { 19. SEC } \\
\text { OF }\end{array}$ & & 20. LIMITATION OF ABSTAACT \\
\hline
\end{tabular}

